\title{
SOCIETY FOR MYCOTOXIN RESEARCH - NEWS AND ANNOUNCEMENTS
}

Hans-Eisenmann-Zentrum
Пा

Technische Universität München

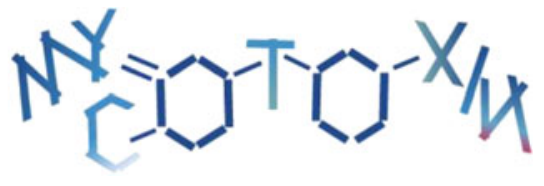

(C) Society for Mycotoxin Research and Springer 2011

\section{Announcement and Call for Papers}

We cordially invite you to join us at the 33rd Mycotoxin

Workshop in Freising, Germany, 30 May - 1 June 2011.

\section{Conference}

The Mycotoxin Workshop is a highly interdisciplinary scientific meeting, covering all facets of mycotoxin research (e.g. biology of production; chemotaxonomy; chemistry and analysis; toxicology; occurrence; impact on agricultural production; public health; prevention and control; et al.).

\section{Organizers}

The conference is organized by the Hans-Eisenmann-Zentrum and the Institute of Animal Hygiene of the Technische Universität München, in cooperation with the Society for Mycotoxin Research.

\section{Conference Venue/Accommodation}

Venue of the workshop is the Kardinal-Döpfner-Haus (www.bildungszentrum-freising.de), Domberg 27, D-85354 Freising, Germany (40 km north-east of Munich, $12 \mathrm{~km}$ distance to Munich Airport). Accommodation (limited capacity!) is also available within the complex of the Kardinal-Döpfner-Haus.

\section{Call for Papers}

You are invited to submit oral or poster presentations. Titles of presentations should be submitted before 11 February 2011. Deadline for abstracts submission is 25 March 2011. Peer-reviewed contributions to this conference will be published in the journal "Mycotoxin Research".

\section{Further Information}

Further details concerning online registration, travel, accommodation, and abstract submission are available via: http://www.wzw.tum.de/hezcongress

We are looking forward to welcoming you in Freising! Johann Bauer

Director of the Hans-Eisenmann-Zentrum and Chair of Animal Hygiene, Technische Universität München Hans-Ulrich Humpf \& Rolf Geisen

Society for Mycotoxin Research

Society for Mycotoxin Research - Secretary

\% Dir. a. Prof. Dr. Manfred Gareis,

Max Rubner-Institute;

Institute for Microbiology and Biotechnology;

E.-C.-Baumann Strasse 20,

D-95326 Kulmbach, Germany 